\title{
RECONSTRUCTION OF DEFECTS OF HEARING AND SPEECH
}

\author{
By Lieut.-Col. Charles W. Richardson, \\ Medical Corps, U. S. A., Washington, D. C.
}

The reconstruction of defects of hearing and speech is organized along the general plan and scope of reconstruction in general, as it has been taken up in connection with the activities of the Division of Physical Reconstruction, Surgeon General's Office.

The object and scope of the administration of these patients is to give them a maximum of physical reconstruction, so that each can be restored physically and mentally to the highest degree functionally that is possible in his handicapped condition. While this physical reconstruction is going on, such treatment is to be employed as to place him economically on as near a perfect basis, when he is discharged, as he was before he came into the service. This is the axiom of the policy and ideals of the Division of Physical Reconstruction.

The administration of this section is under the direction of Lieut.-Col. Charles W. Richardson of the Division of Physical Reconstruction. The assistant is a major, a liaison officer between the Division of Physical Reconstruction and the Section of Otolaryngology, Division of Surgery of the Head.

In order to make efficient the treatment of these patients, it became necessary to enlist therapeutic aides, who had an extensive training in the methods to be employed in the treatment of the adult deaf and in corrective speech work. We have been very fortunate in this section in being able to enlist a large number of most efficient aides in this particular line: in fact, we have listed as candidates the most efficient, capable and intelligent of those engaged in this particular line of therapeutic endeavor.

We have been most fortunate in the selection of our staff. It was a selection in which an error might easily have been made, one which could have been costly to the organization. The superintendent, principal and teachers in connection with this therapeutic endeavor have not only been of the highest type, mentally and 
morally, as well as thoroughly skilled, but they have been so thoroughly enthusiastic in the line of treatment, so thoroughly unselfish in their devotion to the work, and so thoroughly imbued with their responsibility in recalling and reclaiming these men, that they have instilled in their patients the same zeal and enthusiasm. The work has progressed far beyond the most sanguine expectations of those interested in its development.

We find that our cases are subject to two types of treatment. One is purely surgical and medical, due to various lesions of the auditory apparatus and speech organs as well as those having, conjointly with these, other types of disabilities which also demand special lines of medical and surgical treatment. All cases of this type are placed more or less under the medical and surgical attention of the General Staff or the Otolaryngological Staff of the hospital to which the Section of Defects of Hearing and Speech is attached. Besides this we have another type of treatment which is both therapeutic and pedagogic in character. Under this form of treatment come all of the cases which have been mentioned above, as well as a few others which do not require active medical and surgical care.

Therapeutic aides are employed for the purpose, first, of stimulating the impaired hearing function through the auricular method of treatment. This line of treatment is employed for the purpose of stimulating the cerebral auditory center and the temporarily inactive nerve; of restoring synapse between the cerebral centers and the peripheral distribution of the nerve; and of stimulating those cases in which there is simply want of activity in the receptive mechanism. Second, they are employed in that therapeutic endeavor which has for its purpose the employment of one sense to replace the activity of another sense which has been lost through disease or injury. Through the use of speech reading, patients are taught to replace the lost sense of hearing by that of sight.

Besides the auditory cases, we have also a smaller number of patients in which there is more or less impairment of ability to express their thoughts, on account of impairment in the mechanism of speech. Classified under the defects of speech requiring treatment are those affected with:

Mutism, most frequently of shock origin.

Stuttering, stammering, old cases reëstablished, new ones produced during the nervous strain of actual combat. 
Pure aphonia, of nervous origin.

Aphonias, which are due to over-exercise and overstimulation of the vocal cords, giving rise to a pure physical disturbance within the vocal region. These arise from the over-use of the voice, as when an individual under nervous excitement frequently calls out in a loud tone of voice.

There is also a class of cases due to gunshot, shrapnel, grenade, bayonet and other wounds of the upper air tract. It is to be hoped that we will not have many of this type of case, now that trench warfare seems to have been reduced to a minimum. These lesions, with alterations in the voice, were very frequent during the early stages of the war, when trench warfare was the common combatative procedure.

Classified into defects of hearing are those who are nearly deaf, or completely deaf. Of course, this brings into our service a large number of individuals who obtain this near deafness in manifold manners. We have those due to the ordinary diseases of the ear common in civil life-abscess of the ear, both acute and chronic, and acute and chronic catarrh of the middle ear. These are simple infections or secondary to the acute infectious diseases. Many individuals suffering from this type have been admitted into the army with the initial stage of this condition already manifest, or in full activity at the time of admittance into the service.

Those due to warfare are the following: 1. Shock concussion. This type of case is most frequently due to the action of a single high explosive shell in the immediate vicinity of the one affected. Many of these patients eventually recover their hearing completely. 2. Concussion deafness. These cases are usually due to the continuous action of high explosive and shrapnel shell, hand grenades and the more or less continuous play of rapid-fire and machine guns. On account of the continuous concussion transmitted to the labyrinthine structure, there are evident organic changes produced in the internal ear, with the result of permanent impairment of hearing. 3 . The slowly progressive type of concussion deafness as commonly observed in gunners and artillery men. 4. Traumatic, due to casualties about the face, head and auditory apparatus. 5 . Those due to infections contracted in warfare,- - epidemic meningitis, mumps, etc.

After a period of nearly four months, in which the organization theoretically was placed in perfect preparation, this section was given a temporary abode in General Hospital No. 11, at Cape May, 
New Jersey, for the purpose of carrying on its activities. On July 23, the activities were inaugurated at General Hospital No. 11, Cape May, N. J. This was presided over by the commanding officer of the hospital, Col. Paul F. Straub, who made the introductory address, which was followed by a few remarks as to the organization of the section by the director of the Section of Defects of Hearing and Speech. The address of the evening was made by Major W. W. Keen of Philadelphia, who made his topic, "The Comparison of the Surgical Methods of the Civil and the Present War."

The following morning, the actual treatment was started, with seventeen patients. Of these seventeen patients we found four recalcitrants, who could not see any reason why this type of treatment should be carried on. They felt that all had been accomplished that was possible, and they thought that they should be discharged without any further effort being made to place them medically and economically in a better position. Before the end of the first week of treatment, three out of the four patients, after seeing the enthusiastic swing with which the treatment was going on, after noting the progress that their fellows were making, after observing the whole change in the demeanor of their fellows, rapidly fell into line and accepted the benefits that the Surgeon General had placed at their disposal. These patients at the present day rate as the most successful and enthusiastic of those under treatment.

The disturbance of the auditory apparatus, terminating in inlmediate or remote complete and permanent impairment of hearing, is one of the most impressive and distressing among the disabilities that occur during warfare, to an otherwise physically normal man. In our study of the permanently acquired deafness in the adult in civil life, we have been impressed with two important features (not physical) apparently correlated with the loss of hearing, that is, suspicion and social ostracism. These conditions are in no way physically related to deafness, but are more the outcome of the psychology of the deaf mind and the psychology of the non-deaf mind. The deaf person, not hearing what is said about him, becomes necessarily more or less suspicious that general conversation is directed at him personally or relates to his infirmity. We are all well aware that most normal hearing persons have an aversion towards conversing with the hard of hearing or deaf. Add to the 
state of mind thus created the torment of the various physical subjective symptoms, and you necessarily create in the deaf an unhappy state of mind. Contrast a person so afflicted with one afflicted with blindness. The blind has a serene mind born of the knowledge that all mankind extends to him a helping hand, a confidence begotten through the knowledge that universally mankind sympathizes with him and is only too happy to give him succor and aid. These features which have been so common in connection with the deaf or near deaf have been almost entirely absent, or have been eradicated, in connection with our treatment.

Another condition is the modification of the voice, which is attendant on the terrible face injuries produced in modern warfare. It is a singular trait of mankind that he avoids the deaf, and derides the individual who presents difficulty of speech production. These poor individuals are not only subjected to the humiliation on account of their imperfect vocalization, but are subject to the curious observation and scrutiny on account of their facial defects.

It will be the province of the Section of Defects of Hearing and Speech to remove these mental attitudes, first through re-education and corrective work with patients, and second, through correction of the misapprehension of the layman. At the present time, we have a staff of skilled medical officers in connection with the Otolaryngological Section, Division of Surgery of the Head of General Hospital No. 11, coördinating with us in this work. We have also the medico-pedagogic staff in connection with and under the control of the medical officers. We have at the present time twenty-eight patients, an increase of eleven since our work first started. There is no doubt but that we will soon have a large number of patients in this work. We expect the turnover to occur about every three months. Some of these patients will go into limited service, but most of them will be discharged into the hands of the Federal Board for Vocational Education or into their former life.

It would be interesting to tell of some of the marked improvements that these young active intellects have made in connection with their therapeutic work, but we cannot without being invidious show the activities of one as excelling the activities of another. Sufficient it is to say that they have all been enthusiastic, they have vied with each other in their efforts and are all extremely anxious to get well, and make every effort along all lines to accomplish this as rapidly as possible. 